\title{
Epidemiology of chronic rhinosinusitis in Bushehr, southwestern region of Iran: a GA²LEN study*
}

\author{
Afshin Ostovar' ${ }^{1}$, Wytske J. Fokkens², Katayoun Vahdat ${ }^{3}$, Alireza Raeisi ${ }^{3}$, \\ Abdolrasool Mallahzadeh ${ }^{4}$, Shokrollah Farrokhi ${ }^{5 *}$ \\ Rhinology 57: 1, 43 - 48, 2018 \\ https://doi.org/10.4193/Rhin18.061 \\ 'Osteoporosis Research Center, Endocrinology and Metabolism Clinical Sciences Institute, Tehran University of Medical Sciences, \\ Tehran, Iran \\ *Received for publication: \\ March 18, 2018 \\ ${ }^{2}$ Department of Otorhinolaryngology, Academic Medical Center, Amsterdam, the Netherlands \\ Accepted: May 11, 2018 \\ ${ }^{3}$ Department of Infectious Diseases, The Persian Gulf Tropical Medicine Research Center, The Persian Gulf Biomedical Sciences \\ Research Institute, Bushehr University of Medical Sciences, Bushehr, Iran \\ ${ }^{4}$ Department of ENT, The Persian Gulf Tropical Medicine Research Center, The Persian Gulf Biomedical Sciences Research Institute, \\ Bushehr University of Medical Sciences, Bushehr, Iran \\ ${ }^{5}$ Department of Immunology and Allergy, The Persian Gulf Tropical Medicine Research Center, The Persian Gulf Biomedical Re- \\ search Institute, Bushehr University of Medical Sciences, Bushehr, Iran
}

Background: Population-based studies using the European Position Paper on Rhinosinusitis and Nasal Polyps (EPOS) criteria for the assessment of the chronic rhinosinusitis (CRS) prevalence play important roles in the development and promotion of public health policies.

Methods: A multistage, stratified cluster, random sampling method was used to select the study participants from individuals living in Bushehr, which is in the southwestern part of Iran. The standardized Global Allergy and Asthma European Network (GA2LEN) questionnaire was completed by 5,201 participants, and the CRS prevalence were compared among different groups of related factors using chi-squared tests.

Results: The overall CRS prevalence was $28.4 \%$ based on the EPOS criteria, while the self-reported physician-diagnosed CRS prevalence was $20.0 \%$. There was no gender difference; however, CRS was more prevalent in smokers, individuals aged 25-34 years old, non-educated persons, and healthcare workers. CRS was also associated with asthma and allergic rhinitis.

Conclusions: The present study showed that the CRS prevalence in Iran was relatively high. These results support the idea that CRS is a major public health problem in Iran.

Key words: chronic rhinosinusitis, prevalence, GA²LEN study, asthma, allergic rhinitis

\section{Introduction}

Chronic rhinosinusitis (CRS) is characterized by chronic inflammation of the mucosa of the nose and paranasal sinuses resulting in the presence of two or more nasal symptoms, including a blocked nose, pain or pressure around the forehead, nose, or eyes, nasal discharge or postnasal drip, and a reduced sense of smell persisting for at least 12 weeks ${ }^{(1,2)}$.

CRS is a common health problem that can affect productivity and the quality of life, which can burden the healthcare system ${ }^{(3,4)}$. In 2007, the Global Allergy and Asthma European Network $\left(G A^{2} L E N\right)$ conducted a survey to investigate the epidemiology of asthma, allergy and upper airway diseases in adults living in Europe. For CRS, the GA2LEN questionnaire contains questions based on the European Position Paper on Rhinosinusitis and Nasal Polyps (EPOS) criteria ${ }^{(5)}$. The EPOS 2012 epidemiologically defined CRS in adults as the presence of two or more symptoms, one of which is either a nasal blockage/obstruction/congestion or nasal discharge (anterior/posterior nasal drip). The other symptoms are facial pain/pressure and the reduction or loss of smell for a period of at least 12 weeks ${ }^{(1)}$.

In this first European international multicenter study of 19 centers in 12 countries, 57,128 responders participated, and they 


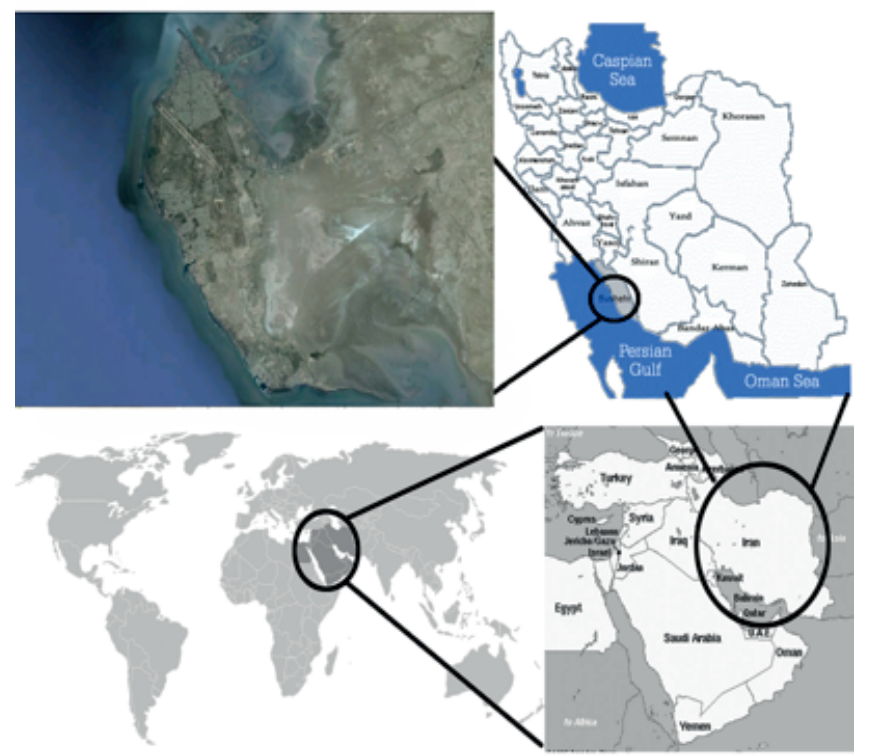

Figure 1. Geographic location of study area: Bushehr, Iran.

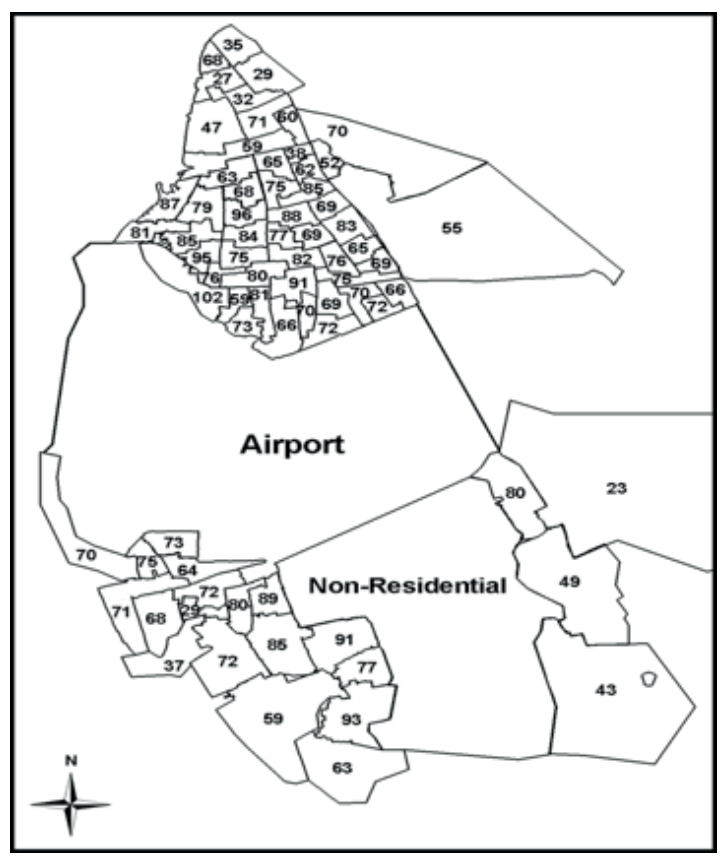

Figure 2. Map of Bushehr and distribution of participants in the Strata. reported an overall CRS prevalence of 10.9\% (range 6.9-27.1\%). In that study, for each of the 19 participating centers, the GA${ }^{2} \mathrm{LEN}$ questionnaire was translated into the local language, and it was posted to randomly selected people aged 15-75 years old (5). Other recent CRS prevalence surveys based on the EPOS definition have shown prevalences of $5.5 \%$ in Brazil ${ }^{(6)}, 8 \%$ in China (7), $11 \%$ in Korea ${ }^{(8)}$, and $12 \%$ in the United States ${ }^{(9)}$.

To date, there has been no large sample-sized, well-designed, population-based study investigating the CRS prevalence in Iran. To the best of our knowledge, this is the first populationbased survey aimed at investigating CRS and its related factors in the Middle Eastern and North African (MENA) region using a validated version of the GA2LEN questionnaire.

\section{Materials and methods}

Study design and sampling

In this population-based, cross-sectional study, a total of 5,420 individuals aged 15-65 years old who had been living for at least one year in the urban areas of Bushehr, Iran were invited to participate. The participants were selected through a multistage, stratified cluster, random sampling method. Bushehr province, with a population of $1,163,400$ ( $1.41 \%$ of Iran), is located in southwestern part of Iran with a hot and dry climate and frequent dusty air pollution episodes (Figure 1). Based on the last national population and housing census in 2016, the population of the city of Bushehr was 300,000 in 2016 with an education and smoking rate of $89.2 \%$ and $20 \%$, respectively (According to the 2016 population census the population of Iran, https:// www.amar.org.ir) ${ }^{(10)}$. The weather of Bushehr is hot and sultry and dusty air pollution occurred in several times in recent years.
Based on the classifications made by the municipality, as shown in Figure 2, we stratified Bushehr to 75 strata. Numbers were assigned to the blocks (as clusters) of each stratum, and then they were randomly sorted. The sample sizes for the strata were determined proportional to the number of households residing in each stratum.

\section{Data collection}

The participants were interviewed personally (face-to-face) in their own houses by trained investigators, and they were invited to participate in the study. If they agreed to participate, they were clarified and asked to complete a standardized questionnaire. Each questionnaire was collected by the investigator the day after the invitation.

The original questionnaire was developed by the $G A^{2} L E N$ project (5), and the GA2 ${ }^{2} \mathrm{LEN}$ questionnaire consists of sociodemographic data, minor and major CRS symptoms, risk factors, and comorbid conditions of allergic diseases. We translated the GA2LEN questionnaire into the Persian language, and a qualified translator back-translated it to English. Then, we compared it to the original English questionnaire to ensure that the translation was good. We checked the final questionnaire for the face-validity of the questions.

We defined CRS based on the EPOS 2012 criteria for epidemiological studies, which stated that the disease consists of inflammation of the nose and the paranasal sinuses characterized by the presence of two or more symptoms. One of these should be either a nasal blockage/obstruction/congestion or nasal discharge (anterior/posterior nasal drip), with or without facial pain/pressure, and with or without a reduction or loss of smell 


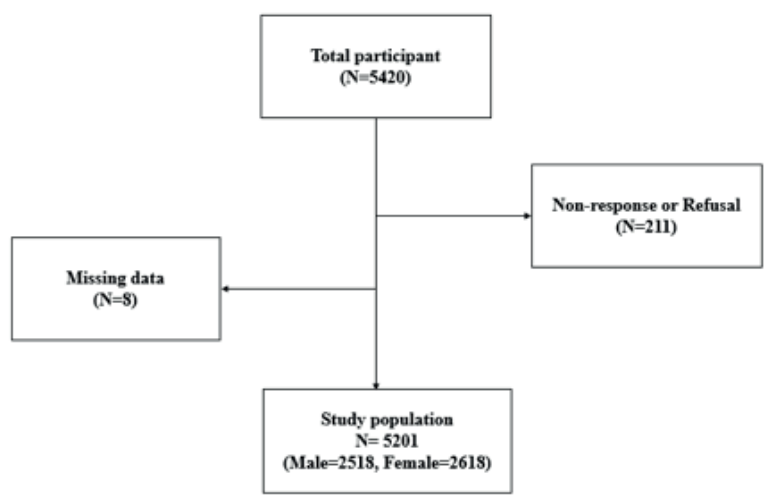

Figure 3. Over review of response rate and study population.

for more than 12 weeks during the last 12 months.

In addition, self-reported physician-diagnosed CRS cases were assessed by a question asking if the participant had "ever been told by a doctor that they had chronic sinusitis" (1). In Iran, CRS can be diagnosed by a general practitioner working in the public or private sector or a specialist, mainly ear nose and throat (ENT), infectious diseases, or asthma and allergy specialists. Moreover, asthma was defined as a positive answer to the question "Have you ever had asthma in the last 12 months?" and at least one of the following 3 symptoms: wheezing or whistling in the chest, waking with breathlessness, or having an asthma attack. Allergic rhinitis and atopic dermatitis were defined as positive answers to the questions "Do you have any nasal allergies including hay fever?" and "Have you ever had an itchy rash that was coming and going for at least 6 months?" respectively. This study was approved by the Ethics Committee of the Bushehr University of Medical Sciences in Bushehr, Iran (ethical approval code: IR.BPUMS.REC.1395.123).

\section{Statistical analysis}

The CRS prevalence was calculated, and it was corresponded to the $95 \%$ confidence intervals (Cls) using the exact binomial method. The CRS prevalence was compared by age group (15-24, 25-34, 35-44, 45-54, and 55-65 years old), gender (male or female), and smoking status (cigarette/water pipe smoker or current smoker) using chi-squared tests. The crude and adjusted odds ratios (ORs) were estimated using multiple logistic regression models in order to investigate the association between CRS and allergy-related conditions (asthma, allergic rhinitis, and ectopic dermatitis). We also calculated the overall agreement and used kappa statistics for the assessment of the agreement between the CRS diagnoses using the EPOS criteria and self-reported physician-diagnosed CRS. P values of $<0.05$ were considered to be statistically significant, and the statistical analyses were performed using IBM SPSS Statistics for Windows, version 21.0 (IBM Corp., Armonk, NY, USA).
Table 1. Socio-demographic characteristics and Risk Factors of Participants, by sex; N (\%).

\begin{tabular}{|c|c|c|c|}
\hline Variable & $\begin{array}{c}\text { Men } \\
2518(49.0)\end{array}$ & $\begin{array}{c}\text { Women } \\
2618(51.0)\end{array}$ & P Value \\
\hline $\begin{array}{l}\text { Age group (year) } \\
-15-24 \\
-25-34 \\
-35-44 \\
-45-54 \\
-55-65\end{array}$ & $\begin{array}{l}491(20.5) \\
588(24.6) \\
499(20.8) \\
503(21.0) \\
314(13.1)\end{array}$ & $\begin{array}{l}698(28.0) \\
595(23.8) \\
526(21.1) \\
387(15.5) \\
290(11.6)\end{array}$ & $<0.001$ \\
\hline $\begin{array}{l}\text { Smoking status (ciga } \\
\text { rette or water pipe) } \\
\text {-Smokers } \\
\text {-Non-smokers }\end{array}$ & $\begin{array}{l}342(13.7) \\
2149(86.7)\end{array}$ & $\begin{array}{l}186(7.2) \\
2395(92.8)\end{array}$ & $<0.001$ \\
\hline $\begin{array}{l}\text { Education level } \\
\text {-University } \\
\text {-High school } \\
\text {-Guidance school } \\
\text {-Primary school } \\
\text {-No education }\end{array}$ & $\begin{array}{l}1144(46.8) \\
789(32.2) \\
337(13.8) \\
132(5.4) \\
45(1.8)\end{array}$ & $\begin{array}{l}1178(47.2) \\
785(31.4) \\
324(13.0) \\
141(5.6) \\
69(2.8)\end{array}$ & 0.230 \\
\hline Health care worker & $66(2.8)$ & $74(3.1)$ & 0.539 \\
\hline Cleaning worker & $43(1.9)$ & 39 (1.6) & 0.652 \\
\hline
\end{tabular}

\section{Results}

A total of 5,201 individuals (49\% men and 51\% women) aged 15-65 years old completed the questionnaires. The overall response rate was $96.1 \%$ among the men and women, equally (Figure 3 ). The mean age was $36.1 \pm 13.5$ years old $(37.3 \pm 13.4$ and $35.0 \pm 13.5$ for the men and women, respectively) $(t(4,890)=5.973$, $\mathrm{P}=0.40$ ). Table 1 shows the sociodemographic characteristics of the participants by sex.

According to the EPOS criteria, 1,425 subjects were diagnosed with CRS, and the overall CRS prevalence was $28.4 \%$ (95\%Cl=27.2-29.6). The prevalence of physician-diagnosed sinusitis was $20.0 \%(95 \% \mathrm{Cl}=19.0-21.0)$, and the overall agreement between the EPOS criteria and physician-diagnosed CRS was $77.6 \%$ (kappa=0.39, $\mathrm{P}<0.001)$.

The CRS prevalences among the men and women were $28.2 \%$ and $28.4 \%$, respectively $(X 2(1)=0.017, P=0.895)$. The highest prevalence (32.7\%) was observed among the participants in the $15-34$ years old age group $(X 2(4)=36.7, P<0.001)$. CRS was also more prevalent among smokers $(X 2(1)=45.1, P<0.001)$, people with no education $(X 2(4)=22.8, P<0.001)$, healthcare workers $(\mathrm{X} 2(1)=12.0, \mathrm{P}=0.001)$, and those with cleaning-related jobs $(X 2(1)=54.6, P<0.001)$. Table 2 shows the CRS frequency according to the sociodemographic level and related factors by sex. The CRS symptom prevalence was as follows: nasal blockage $18.5 \%$, pain or pressure around the forehead, nose or eyes $28.2 \%$, discolored nasal discharge (snot) or discolored mucus in the throat $33.7 \%$, and a reduction or absence of the sense of smell (19.2\%).

The CRS prevalence was higher among the participants with 
Table 2. Prevalence of CRS among the participants, by sex.

\begin{tabular}{|c|c|c|c|c|c|}
\hline \multicolumn{2}{|l|}{ Variable } & $\begin{array}{c}\text { Men } \\
{[\mathrm{N}=685(28.18 \%)]}\end{array}$ & P value & $\begin{array}{c}\text { Women } \\
{[\mathrm{N}=\mathbf{7 2 0}(\mathbf{2 8 . 3 5} \%)]}\end{array}$ & $P$ value \\
\hline \multirow{5}{*}{ Age group } & $15-24$ & $109(22.9)$ & \multirow{5}{*}{0.01} & $147(21.7)$ & \multirow{5}{*}{$<0.001$} \\
\hline & $25-34$ & $174(30.6)$ & & $201(34.3)$ & \\
\hline & $35-44$ & $143(29.4)$ & & $162(32)$ & \\
\hline & $45-54$ & $145(30.2)$ & & 99 (26.6) & \\
\hline & $55-64$ & $74(24.2)$ & & $83(27.4)$ & \\
\hline \multirow{5}{*}{ Education level } & No education & $19(44.1)$ & \multirow{5}{*}{$<0.001$} & $26(39.3)$ & \multirow{5}{*}{0.01} \\
\hline & Primary School & $40(32)$ & & $55(39.5)$ & \\
\hline & Secondary School & $108(33.3)$ & & $82(26.9)$ & \\
\hline & High School & $231(30.4)$ & & $208(27.2)$ & \\
\hline & University & $271(24.1)$ & & $323(27.9)$ & \\
\hline \multirow{2}{*}{ Smoking } & Non-smoker & $547(26.2)$ & \multirow{2}{*}{$<0.001$} & $635(27.1)$ & \multirow{2}{*}{$<0.001$} \\
\hline & Smoker & $130(40)$ & & $70(41.1)$ & \\
\hline \multicolumn{2}{|l|}{ Health care worker } & $17(40.4)$ & 0.06 & $18(50)$ & 0.002 \\
\hline \multicolumn{2}{|l|}{ Cleaning worker } & $41(62.1)$ & $<0.001$ & $34(27.5)$ & $<0.001$ \\
\hline
\end{tabular}

asthma (OR=4.1, 95\%Cl=3.4-5.0, $\mathrm{P}<0.001)$, allergic rhinitis $(\mathrm{OR}=4.9,95 \% \mathrm{Cl}=4.3-5.6, \mathrm{P}<0.001)$, and atopic dermatitis $(\mathrm{OR}=3.4,95 \% \mathrm{Cl}=3.0-3.9, \mathrm{P}<0.001)$. The multiple logistic regression showed that the associations remained statistically significant after making adjustments for sex, age, educational level, and smoking. Adjusted ORs for the associations of asthma, allergic rhinitis, and atopic dermatitis were $(\mathrm{OR}=3.9,95 \% \mathrm{Cl}=3.2-$ 4.9, $\mathrm{P}<0.001),(\mathrm{OR}=4.7,95 \% \mathrm{Cl}=4.1-5.4, \mathrm{P}<0.001)$, and $(\mathrm{OR}=3.4$, $95 \% \mathrm{Cl}=3.0-3.9, \mathrm{P}<0.001)$, respectively.

\section{Discussion}

The findings of this study showed that the overall CRS prevalence based on the EPOS criteria in Bushehr was as high as $28.4 \%$. We also found that the physician-diagnosed CRS prevalence was $20 \%$ in the general population. There was fair agreement between the two methods.

The CRS prevalences reported from different parts of the world range from $1 \%$ in Korea to higher than $28 \%$ in Portugal $(5-7,9,11)$. In addition, some studies have reported that CRS is more prevalent in the southern geographical latitudes than the northern ones $(5,9,12)$. One survey in the United States showed that CRS was more common in the southern regions ${ }^{(9)}$. The prevalence of CRS in Bushehr, which has a hot and dry climate, was the highest among those studies conducted using EPOS criteria. Therefore, according to the CRS impact on health and the quality of life, it is an important public health issue in Bushehr ${ }^{(13)}$.

There are some explanations for the higher CRS prevalence in Bushehr. For example, our previous study showed that the frequency of indoor aeroallergens, such as house dust mites, fungi, and cockroaches, was high in Bushehr ${ }^{(14)}$. Another study confirmed that dust storms, which occur frequently in Bushehr, induce allergic inflammation ${ }^{(15)}$. However, further studies are needed to investigate the causes and consequences of CRS in Bushehr, and also to examine the prevalences in other parts of the country and the region.

There was fair agreement between the physician-diagnosed CRS cases and the diagnoses based on the EPOS criteria, which was consistent with results of the European study ${ }^{(5)}$. This may have been because approximately one-third of the individuals were not aware of their condition, likely because they did not know the symptoms, or the condition had not been diagnosed by a physician.

Based on the findings of the present study, the CRS prevalence was not significantly different between the men and women. There are studies from the United States ${ }^{\left({ }^{9}\right)}$ and Canada ${ }^{(12)}$ reporting higher prevalences among women, while another study from China reported a higher prevalence among men ${ }^{(7,16)}$. Moreover, this study revealed that the highest CRS prevalence was in those participants aged 25-34 years old. The Chinese study also reported a higher prevalence in individuals aged 15-34 years old ${ }^{(7)}$, while some other studies reported the highest CRS prevalence among the older age groups ${ }^{(5,7,9,12)}$. The higher prevalence in this younger age group may be because they are more likely to be exposed to occupational and environmental factors. Our findings showed that smoking was significantly associated with CRS in both men and women. Studies often report a positive association between CRS and smoking $(7,9,17)$, and they have confirmed smoking as a risk factor for CRS ${ }^{(17-19)}$. The prevalence of smoking tobacco in Bushehr is relatively high, and the prevalence of water pipe smoking is significantly higher than in other 
regions of Iran ${ }^{(20)}$. This may contribute partly to the high CRS prevalence in Bushehr.

We also found that those individuals with lower educational levels had a significantly higher CRS prevalence when compared to those with higher educational levels. Moreover, those participants whose jobs were related to cleaning also showed a higher prevalence. We found some evidence supporting this finding and confirming the fact that CRS is more prevalent among lower socioeconomic status individuals $(6,11,21)$.

Finally, there was a strong association between CRS and other allergic conditions, such as asthma, allergic rhinitis, and eczema. This finding was also consistent with the body of evidence confirming that CRS is commonly comorbid with asthma and allergic rhinitis ${ }^{(7,22-24)}$. Moreover, one previous study showed that there was a strong association between CRS and asthma at all ages and both genders, and this association with asthma was stronger in those reporting both CRS and allergic rhinitis ${ }^{(22)}$. Our previous population-based study using the International Study of Asthma and Allergies in Childhood (ISAAC) questionnaire showed that asthma, allergic rhinitis, and eczema were more prevalent in Bushehr than in the other cities of Iran ${ }^{(25)}$.

\section{Strengths and limitations}

This is the first large sample-sized, population-based survey on the CRS prevalence in the region. We used epidemiological criteria for the definition of CRS, but it is a condition that should be clinically confirmed. This may have introduced a misclassification that, more than likely, overestimated the CRS prevalence.
Moreover, because the questionnaires were completed by the participants, some of the data was missing for some of the questions. However, our analyses showed that this was not influential. Finally, any generalization of these findings should be made with caution because the population of Bushehr is hardly representative of the Iranian population.

\section{Conclusion}

The results of the present study showed that the CRS prevalence in Bushehr was relatively high. This supports the idea that CRS is a major public health problem in Iran. Therefore, we suggest further studies on the causes of this higher CRS prevalence in Iran, and further investigations into the health and economic burdens of this disease.

\section{Acknowledgement}

This study was funded by Bushehr University of Medical Sciences (BPUMS), Iran.

\section{Authorship contribution}

AO drafted the manuscript, performed data analysis and interpretation, participated in study design and conduction. WF, KV, $A R$, and $A M$ participated in study design and reviewed the manuscript. SF conceived the study, helped draft the manuscript, participated in study design and conduction.

\section{Conflict of interest}

The authors declare that they have no conflict of interest.

\section{References}

1. Fokkens WJ, Lund VJ, Mullol J, et al. EPOS 2012: European position paper on rhinosinusitis and nasal polyps 2012. A summary for otorhinolaryngologists. Rhinology. 2012;50(1):1-12

2. Kato A. Immunopathology of chronic rhinosinusitis. Allergol Int. 2015;64(2):121-30.

3. Gliklich RE, Metson R. The health impact of chronic sinusitis in patients seeking otolaryngologic care. Otolaryngol Head Neck Surg. 1995;113(1):104-9.

4. Smith KA, Orlandi RR, Rudmik L. Cost of adult chronic rhinosinusitis: A systematic review. Laryngoscope. 2015;125(7):1547-56.

5. Hastan D, Fokkens WJ, Bachert C, et al Chronic rhinosinusitis in Europe--an underestimated disease. A GA(2)LEN study. Allergy. 2011;66(9):1216-23.

6. Pilan RR, Pinna FR, Bezerra TF, et al. Prevalence of chronic rhinosinusitis in Sao Paulo. Rhinology. 2012;50(2):129-38.

7. Shi JB, Fu QL, Zhang H, et al. Epidemiology of chronic rhinosinusitis: results from a cross-sectional survey in seven Chinese cities. Allergy. 2015;70(5):533-9.

8. Kim JH, Cho C, Lee EJ, et al. Prevalence and risk factors of chronic rhinosinusitis in South
Korea according to diagnostic criteria. Rhinology. 2016;54(4):329-35.

9. Hirsch AG, Stewart WF, Sundaresan AS, et al. Nasal and sinus symptoms and chronic rhinosinusitis in a population-based sample. Allergy. 2017;72(2):274-81.

10. Yousefi F, Darabi H, Nabipour I, et al. Prevalence of Tobacco Smoking in Bushehr Province: Comparison of Two Phases of the Persian Gulf Healthy Heart Study. Iranian South Medical Journal. 2014;17(3):487-95.

11. Kim YS, Kim NH, Seong SY, et al. Prevalence and risk factors of chronic rhinosinusitis in Korea. Am J Rhinol Allergy. 2011;25(3):11721.

12. Chen $Y$, Dales $R$, Lin M. The epidemiology of chronic rhinosinusitis in Canadians. Laryngoscope. 2003;113(7):1199-205.

13. Slovick A, Cornet M, Surda P, Tomazic PV. Chronic rhinosinusitis: New understanding of specific and general Quality of life scores. Rhinology. 2016;54(4):289-91.

14. Farrokhi S, Gheybi MK, Movahed A, et al. Common aeroallergens in patients with asthma and allergic rhinitis living in southwestern part of Iran: based on skin prick test reactivity. Iran J Allergy Asthma Immunol. 2015;14(2):133-8. 15.
15. Gheybi MK, Movahed AM, Dehdari R, et al. Dusty Air Pollution is Associated with an Increased Risk of Allergic Diseases in Southwestern Part of Iran. Iran J Allergy Asthma Immunol. 2014;13(6):404-11.

16. Pleis JR, Lethbridge-Cejku M. Summary health statistics for U.S. adults: National Health Interview Survey, 2006. Vital Health Stat 10. 2007(235):1-153.

17. Yamin M, Holbrook EH, Gray ST, et al. Cigarette smoke combined with Toll-like receptor 3 signaling triggers exaggerated epithelial regulated upon activation, normal T-cell expressed and secreted/CCL5 expression in chronic rhinosinusitis. J Allergy Clin Immunol. 2008;122(6):1145-53

18. Reh DD, Higgins TS, Smith TL. Impact of tobacco smoke on chronic rhinosinusitis: a review of the literature. Int Forum Allergy Rhinol. 2012;2(5):362-9.

19. Goldstein-Daruech N, Cope EK, Zhao KQ, et al. Tobacco smoke mediated induction of sinonasal microbial biofilms. PLoS One. 2011;6(1):e15700.

20. Mehboudi MB, Nabipour I, Vahdat K, et al. Inverse association between cigarette and water pipe smoking and hypertension in an elderly population in Iran: Bushehr elder- 
ly health programme. J Hum Hypertens. 2017;31(12):821-5.

21. Thilsing $T$, Rasmussen J, Lange $B$, et al Chronic rhinosinusitis and occupational risk factors among 20- to 75-year-old Danes-A GA(2) LEN-based study. Am J Ind Med. 2012;55(11):1037-43.

22. Jarvis D, Newson R, Lotvall J, et al. Asthma in adults and its association with chronic rhinosinusitis: the GA2LEN survey in Europe. Allergy. 2012;67(1):91-8.

23. Yoshimura K, Kawata R, Haruna S, et al. Clinical epidemiological study of 553 patients with chronic rhinosinusitis in Japan. Allergol Int. 2011;60(4):491-6

24. Phillips KM, Hoehle LP, Bergmark RW, et al. Chronic rhinosinusitis severity is associated with need for asthma-related systemic corticosteroids. Rhinology. 2017;55(3):211-7.

25. Farrokhi S, Gheybi MK, Movahhed A, et al. Prevalence and risk factors of asthma and allergic diseases in primary schoolchildren living in Bushehr, Iran: phase I, III ISAAC protocol. Iran J Allergy Asthma Immunol. 2014;13(5):348-55.
Shokrollah Farrokhi, MD, PhD

Department of Immunology and

Allergy

the Persian Gulf Tropical Medicine

Research Center

Bushehr University of Medical Scien-

ces

Bushehr

Iran

PO Box: 7516688876

Tel/Fax: +98 7733320361

Mobile: 0917-716-7965

E-mail: Farrokhi_Sh@yahoo.com,

sh.farokhi@bpums.ac.ir 